\title{
Country focus
}

"Country focus" includes news of a more detailed and substantive kind than the news items given in "News from the Statistical Offices".

\section{Turkey}

\section{Social Structure and Women Statis- tics}

A Division named Social Structure and Women Statistics has been established within the Department of Statistical and Econometric Evaluations for the purpose of supporting the foundation and the development of a data base for statistics and indicators on women in the State Institute of Statistics in 1993.

Data reflecting the social structure and the situation of women exists in the State Institute of Statistics. However, these data should be re-evaluated and analyzed. The results of studies conducted by other institutions will form additional data sources. This database will also be used within the National Programme for the Enhancement of Women's Integration in Development conducted by the United Nations Development Programme.

The work plan of the State Institute of Statistics is:

- A compilation of main demographic indicators pertaining to women, e.g., fertility, mortality, marriage;

- A comparative analysis of economi- cally active men and women according to the socio-economic characteristics by provinces, - An analysis of the socio-economic characteristics of housewives, - A detailed analysis of the women in labour force,

- A comparative analysis of men's migration with that of women within the country,

- Estimating the probability of girls and boys taking advantage of primary school education, measuring the progress of these to other formal education levels,

- Determination of gender segregation in income distribution,

- To make specialized research reflecting the position of women in Turkey,

- To cooperate with the State Personnel Presidency for the preparation of a survey determining the socio-economic characteristics of public employees in Turkey.

\section{Publication}

Women in Statistics, 1927-1992 (Turkish-English)

\section{Working Papers}

- Women in Public Sectors (Turkish),

- Main Women Indicators, Turkey 1978-1993 (Turkish-English),

- Regional Women Statistics, 1990 (Turkish), 
- Internal Migration by Gender, Turkey 1985-1990 (English),

- Formal Education by Gender, Turkey 1980-1992 (English),

- Employees in the Manufacturing Industry by Gender, Turkey 19831990 (English).

\section{United Kingdom}

Proposed Merger of the Central Statistical Office and the Office of Population Censuses and Surveys

The Central Statistical Office (CSO) and the Office of Population Censuses and Surveys (OPCS) are to be co-located at Drummond Gate, Pimlico in London. The moves are planned for early in 1996.

It is also proposed that on 1 April 1996 the two organizations should be merged to form a new Government "Next Steps" Agency. The Agency would be independent of any other Government Department. It would be accountable to the Chancellor of the Exchequer. It would be headed by Dr. D. Holt, whose appointment as Head of the Government Statistical Service and Chief Executive of the CSO was recently announced. In addition to his existing appointments, Dr. Holt would become Registrar General for England and Wales. The new Agency would have a staff of about 3200 and an annual budget of $£ 125$ million.

\section{Functions and Responsibilities}

The Agency would take over all the existing functions of $\mathrm{CSO}$ and OPCS, including OPCS's responsibilities for the Registration Service.

In addition it would be charged with establishing and maintaining a central database of key economic and social sta- tistics, drawn from the whole range of statistics produced by Government, and produced to common classifications, definitions and standards. As well as providing statistics required by Government, it would have the responsibility of ensuring that statistics from the central database were widely and speedily available, in the form of regular publications and in response to specific requests. It would publish compendia, analyses and commentary, bringing together statistics from different sources and series and presenting a statistical picture of economic and social trends and developments both nationally and sub-nationally.

The content of the proposed database (the "key statistics") has not yet been defined. Nor have the classifications, definitions and standards. These would be a task for the Agency, in consultation with other Government Departments, data suppliers and users of statistics, building on work which is already being done within the Government Statistical Service (GSS). The content of the database would be kept under regular review.

The proposed functions of the Agency are summarized in Annex 1.

\section{Geographic Coverage}

The geographical coverage of CSO's and OPCS's responsibilities varies. The CSO's primary role is to compile and disseminate statistical estimates needed for UK government central economic management although in many areas it relies on contributions from Northern Ireland departments. Most of OPCS's responsibilities extend only to England and Wales, but OPCS has some wider coordinating responsibilities. This will continue. It is not proposed to transfer to the Agency any of the existing responsi- 
bilities of Scottish or Northern Irish Departments. However, the proposed Agency database would have UK coverage.

\section{Benefits of the Proposed Merger}

The purpose of the proposals is to meet a widely perceived need for greater coherence and compatibility in Government statistics, for improved presentation and for easier public access. The changes should:

- improve the quality of the statistical support available to the Government for national policy-making;

- improve the service available to non-Government users of Government statistics;

- support the Government's Open Government policies as set out in the 1993 White Paper, a relevant extract from which can be found in Annex 2;

- enable better informed decisions to be taken about statistical priorities, both within the Agency and more widely within Government;

- enable gaps in Government statistics to be identified and tackled more easily;

- put the Agency in a strong position to exploit technological developments, including electronic dissemination.

Implications for Statistical Work of other Government Departments

The GSS is a part-centralized, part-decentralized service. Most Government Departments employ their own statisticians, who are responsible for producing and publishing statistics on particular subjects, and for providing statistical advice to Departmental Ministers. This ar- rangement will continue. The Agency proposals do not remove from Departments any of their existing responsibilities, although some changes in responsibilities would not be ruled out where individual examination showed them to be sensible and cost-effective.

The classifications an definitions used by Departments are sometimes dictated by their own operational needs, or by statutory requirements. The propo-sals would not change this, but Departments might be asked to provide information for the Agency database in a different form in accordance with the necessary classifications, definitions and standards.

\section{Confidentiality and Security of Sensitive Data}

The database of key statistics would hold only aggregated and anonymous data.

Existing CSO and OPCS policies and practices in respect of the confidentiality and security of data would continue, and would be brought together in a consolidated code for the new Agency.

\section{Timing of Improvements}

Some improvements in statistics are expected as a result of work already in hand, and from bringing CSO and OPCS together. However, considerable work is needed to plan and establish the new database, and to arrange for the supply of data to it in an appropriate form. Supply of some of the data may require modification of Departments' collection and processing systems. The cost of these modifications could be considerable if they are not made as part of Departments' own modifications of their systems. 
It would therefore be some years before the full potential of the new arrangements could be realized.

\section{Advisory and Consultative Machinery}

Simultaneously with the establishment of the Agency it is proposed to establish an Advisory Committee which would advise the Head of the Government Statistical Service, and through him the Government, on statistical issues and priorities generally. This Committee would also act as Advisory Committee to the Agency itself.

Existing subject specific advisory and consultative bodies would continue.

\section{Annex 1}

\section{Functions of Proposed New Agency}

- To collect, compile and analyse economic and social statistics and disseminate the statistics and the analyses.

- To assemble, catalogue, document and make available a database of key statistics to provide a picture of society and a window on the work and performance of government.

- To develop and/or be the custodian of standards, definitions and classifications used across the GSS, including those to be followed by departments in producing statistics which are input to the key statistics series.

- To coordinate the operations of departments and agencies in relation to statistical work, with particular regard to,

- avoidance of duplication,

- the attainment of compatibility between and the integration of statistics compiled, and
- the maximum utilization of the statistics collected, and the collection processes.

- To administer the marriage laws and to run the registration of "vital" events systems.

- To maintain and administer the NHS Central Register, and other registers as required.

- To provide liaison between the UK, other countries and international organizations in relation to statistical and registration matters, and where appropriate represent and safeguard UK interests when standards, procedures and practices are being developed.

- To carry out the central functions required by a de-centralized statistical service.

\section{Annex 2}

\section{Official Statistics}

2.27. Official statistics contain a vast range of information about the economy and society. They are collected by government to inform debate, decisionmaking and research both within government and by the wider community. They provide an objective perspective of the changes taking place in national life and allow comparisons between periods of time and geographical areas.

2.28. Vital as this is, open access to official statistics provides the citizen with more than a picture of society. It offers a window on the work and performance of government itself, showing the scale of government activity in every area of public policy and allowing the impact of government policies and actions to be assessed.

2.29. Reliable social and economic statistics are fundamental to the Citi- 
zen's Charter and to open government. It is the responsibility of government to provide them and to maintain public confidence in them.

2.30. Since the Central Statistical Office (CSO) became an agency it has announced certain improvements which mean that:

- all CSO statistics are now published as early as possible, with many being released much more quickly than before;

- CSO data are made available to all users at the same time, although Ministers, and where appropriate the Governor of the Bank of England, and some officials (on a strict needto-know basis) receive copies of key statistical releases $1 \frac{1 / 2}{2}$ days in advance;

- the integrity of the statistics has been demonstrated by making it clear that the CSO is entirely responsible for the contents of its press releases, subject only to advance consultation with the Chancellor of the Exchequer or the Economic Secretary on changes in format.

2.31. Other departments, in consultation with the Head of the Government Statistical Service, are also introducing measures to help ensure the consistency of release practice for key official statistics.

\section{United States}

National Centre for Health Statistics, Centres for Disease Control and Prevention

New Leadership

After 12 years as NCHS Director, Dr. Manning Feinleib stepped down as Di- rector of the Centre on January 31 . He is now at the Georgetown University Medical Centre, where he is research professor in the Department of Medicine. In his new position, Dr. Feinleib is pursuing long-standing interests in epidemiology and international health. For more than a decade, Dr. Feinleib led the Centre into many new areas and expanded or established programs to meet the growing need for comprehensive vital and health statistics.

The Centres for Disease Control and Prevention has initiated a nationwide search for a new Director for NCHS. A Search Committee co-chaired by Dr. James Marks, newly-named Director of CDC's National Centre for Chronic Disease Prevention and Health Promotion, and Dr. Donald Lindberg, Director, National Library of Medicine is beginning its work. The large Search Committee's diverse membership reflects the many facets of NCHS's programs and its role in both public health and the Federal statistical community. The position has been advertised widely and the announcement for the Senior Executive Service vacancy will close on July 31 , 1995. It is anticipated that a new Director could be in place, possibly by the end of the year.

In the interim, NCHS Deputy Director Jack Anderson is serving as Acting Director. Dr. Jennifer Madans is serving as Acting Deputy Director. Dr. Madans is the Director of the Division of Epidemiology, Office of Analysis, Epidemiology and Health Promotion. Mr. Robert Israel, Associate Director for International Statistics, retired after almost 30 years at NCHS. He served for a decade as NCHS Deputy Director, but most recently directed its international program. Dr. Robert Hartford is serving as Acting Director of the Division of International 
Statistics and heading up the international statistics efforts at NCHS.

National Health Interview Survey Redesign Planned for 1996

NCHS's National Health Interview Survey (NHIS), a major source of information on the health of Americans, is undergoing a extensive redesign. In operation since 1957, it provides current and trend data to describe the extent of illness and disability; use of health services; health care coverage; health habits, knowledge and attitudes of the U.S. population. As the largest populationbased health survey in the United States, the NHIS collects data on many of the nation's critical public health issues and works in close collaboration with other agencies to develop it's content and scope.

The goal of the NHIS redesign is to improve its capacity to provide data on all aspects of health required for monitoring, research and policy purposes. The survey redesign updates content to meet current data needs, includes additional aspects of health, reduces respondent burden, and employs state-ofthe-art questionnaire development. It will be administered through computerassisted-personal interviewing which will facilitate data processing and analysis as well as speed and improve access to the data. The redesign will also enhance linkages with other data systems and surveys. It will be implemented in January 1996. During the past two years, the NHIS conducted the largest-ever survey of disability in the United States and implemented a component to measure access and barriers to care.

\section{Recent Program Accomplishments}

The Third National Health and Nutrition Examination Survey was recently completed and produced landmark data on key indicators of the Nation's health. New estimates of cholesterol and blood lead levels, dietary fat, overweight, and hypertension have been released. The National Health Care Survey has now fielded all of the component surveys to monitor health care in America. Surveys of ambulatory surgery, home health and hospice care, and emergency and outpatient departments are now in place along with existing surveys of inpatient, nursing home and ambulatory care.

Two new surveys provide important health information. The National Employers Health Insurance Survey was developed and fielded to analyze employer-provided health insurance benefits and choices and produce national and state health accounts. The State and Local Immunization Coverage and Health Survey monitors the level at which children aged 19 to 35 months are receiving immunizations as part of the Nation's childhood immunization initiative.

\section{New International Mortality Chartbook Published by NCHS}

International Mortality Chartbook, Levels and Trends, 1955-91 contains figures showing country rankings and trends for selected causes of death and variations in patterns of mortality in the United States and 40 industrialized countries. Tables showing mortality rates from selected causes for each country are also provided. The chartbook is designed to facilitate international comparisons of mortality patterns 
by presenting information ordinarily unavailable or difficult to obtain in standardized formats. Data from the U.S. National Vital Statistics System were combined with those provided by the World Health Organization. The report is available from the National Centre for Health Statistics. This data base will soon be available on diskette The data base supports comparative analysis of mortality patterns by cause of death, age, and sex, from 1955 to 1991. Data are provided in Lotus spreadsheets which contain age-specific and agestandardized death rates as well as life expectancy. All spreadsheets are provided separately for both sexes combined and separately for males and females. The data base also contains deaths and estimated populations so that the user can create specialized rates tailored to specific projects or analyses. Contact NCHS, 6525 Belcrest Road, Hyattsville, Maryland 20782, (301) 4368500 , for ordering information. 